\title{
Research the Effects of Thoracic and Lumbar Support Fixtures on Forward Head Posture during Visual Display Terminal Work
}

\author{
Yeoung-Sung Kim, PT • Han-Kyu Park, PT, MS ${ }^{1}$ Min-Chull Park, PT, PhD ${ }^{2 \dagger}$ \\ Department of Physical Therapy, Graduate School, Catholic University of Pusan \\ ${ }^{1}$ Department of Physical Therapy, Graduate School, Daegu University \\ ${ }^{2}$ Department of Physical Therapy, College of Health Sciences, Catholic University of Pusan
}

Received: May 11, 2016 / Revised: May 11, 2016 / Accepted: May 16, 2016

(c) 2016 J Korean Soc Phys Med

\section{| Abstract |}

PURPOSE: Forward head posture (FHP) is one of the most common postural problems among white-collar workers who perform highly repetitive tasks in the same position. The aim of this study was to research the effects of thoracic and lumbar support fixtures on forward head posture (FHP) during visual display terminal (VDT) work.

METHODS: The subjects were 36 healthy male students with no problems in their medical history or respiratory systems. The subjects were randomly assigned to three groups: control group $(\mathrm{n}=12)$, thoracic support fixtures $(n=12)$, and lumbar support fixtures $(n=12)$. We conducted a text typing task of the same content for 20 minutes, and evaluated the angles, including the craniovertebra angle (CVA), craniorotation angle (CRA) with photogrammetry.

RESULTS: The thoracic and lumbar support fixture groups showed a statistically significant difference at the CVA and CRA to the control group $(\mathrm{p}<.05)$, and the post-hoc

†Corresponding Author : mcpark@cup.ac.kr

This is an Open Access article distributed under the terms of the Creative Commons Attribution Non-Commercial License (http://creativecommons.org/licenses/by-nc/3.0) which permits unrestricted non-commercial use, distribution, and reproduction in any medium, provided the original work is properly cited. test showed an increase of the CVA and decrease of the CRA than the control group. However, when we compared the effects of thoracic and lumbar support fixtures on FHP, there was no significant difference in the difference in decrease of the CVA or increase of the CRA ( $\mathrm{p}>.05)$.

CONCLUSION: We determined that VDT work using thoracic and lumbar support fixtures has a positive effect on forward head posture in white-collar workers. Further studies are required to find the more effective location of support fixtures.

Key Words: CRA, CVA, FHP, Support fixtures

\section{Introduction}

Long hours of sedentary work using computers can increase tension and the pressure load in muscles around the neck. They can also cause a forward head posture (FHP) along with diseases around the neck and shoulder (Mekhora et al., 2000; Szeto et al., 2005). A decrease in lumbar lordosis during work not only increases normal thoracic kyphosis, but it is also closely associated with movements of the head and cervical spine (Quek, 2013). FHP is a type of head postural problem involving a mal-alignment of the 
cervical spine and involving pain. It can be recognized in the positioning of the external auditory meatus forward of a vertical line crossing the acromion (Chiu, 2002). FHP causes an increase in the flexion of the lower cervical spine and the extension of the upper cervical spine (Sahrmann, 2011; Salahzadeh et al., 2014; Cuccia, 2009). It causes not only pain in the cervical spine but also secondary musculoskeletal problems such as the herniation of the lumbar disc, rounded shoulders, and posture changes involving systemic imbalance (Feffari and Russell, 2003; Yoo and lee, 2016). In order to correct these poor postures, various methods have been developed. As a fundamental solution to correct spinal alignment while sitting in an office chair, support fixtures can be applied (Ukita et al., 2015).

It has been shown that support fixtures can control thoracic kyphosis and have a significant effect on the cervical spine's range of motion, especially rotation and flexion (Ko, 2011). Decreased thoracic kyphosis is also shown to have a direct effect on the cervical spine and to reduce FHP. Maintaining normal lordosis of the cervical spine also sustains appropriate thoracic kyphosis and has the indirect effect on the cervical spine of reducing FHP (Kendall, 2010). Goda (2015) and Ko (2011) reported that the use of support fixtures reduces the activities of the postural muscles and decreases muscle fatigue, which consequently can prevent thoracic kyphosis and FHP. Especially, the lumbar support fixtures promote maintenance of the natural spine curve when sitting, as a result, head and neck posture will be adversely affected by changes lower down in the spine. Therefore, the lumbar support fixtures as a therapeutic intervention was efficient for postural correction of the spine posture (Mckenzie and May, 2003). Eventually, support fixtures influence the articular capsules, ligaments, and muscles around the cervical, thoracic, and lumbar spine through a sensorimotor system to maintain a neutral posture (Ko, 2011).

Therefore, this study explores the effects of applying thoracic and lumbar support fixtures on movement of the head and neck during visual display terminal (VDT) work in a sitting posture. The study also investigates the necessary positioning of the support fixtures to prevent FHP.

\section{Method}

\section{Subject}

This study consisted of 36 healthy students in their 20 s living in Pusan. The purpose and method of the study were explained to the participants, and all agreed to take part in the experiment voluntarily. The study adhered to the ethical principles of the Declaration of Helsinki.

Persons with any medical history in relation to car accident including fracture, neuromuscular disorder, severe scoliosis, falling accident and cervical spine surgery, functional impairment of the lumbar vertebra or lower limb, and respiratory problems were excluded, in addition to those who undertook, strenuous exercise involving the upper limb muscles.

\section{Measurement}

The students were divided into three groups of 12 persons each: a group with the lumbar support fixture, another group with the thoracic support fixture, and the final group with no support fixture. The method of this study was based on Ministry of Labor Notification for VDT Management. To take account of physical differences in the subjects, height adjustable desks and chairs were used. The elbow and back postures of each participant were controlled to maintain a range between 90 and 100 degrees. The viewing angle of each participant was controlled to maintain their gaze at a position 10 to 15 degrees from the top to the bottom of the monitor. The viewing distance was controlled to maintain a distance of at least $40 \mathrm{~cm}$. Each participant was asked to maintain a comfortable sitting posture, with his or her bare feet placed on a feet-shaped 


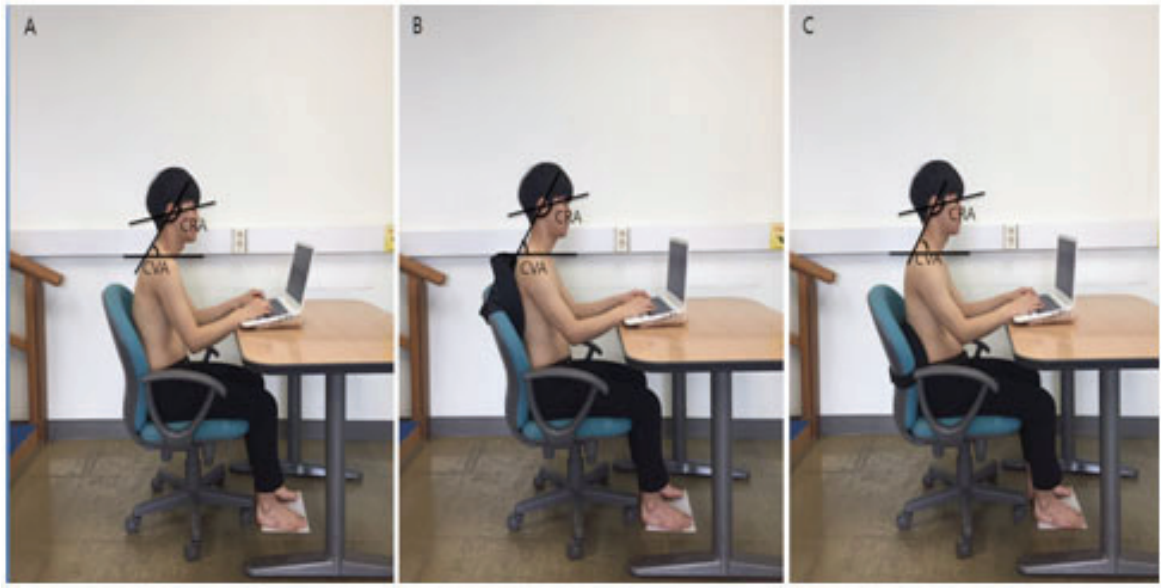

Fig. 1. Measuring posture (A: control group, B: thoracic support fixture, C: lumbar support fixture)

paper sheet. With their knee-joints bent 90 degrees and maintaining a natural posture, each participant conducted a text typing task of the same content for $20 \mathrm{~min}$ (Heo, 2006; Lee, 2013). To assess movements of the head according to the application of the lumbar and thoracic support fixtures, the craniovertebral angle (CVA) and craniorotation angle (CRA) were used as the test indices. The CVA and CRA were used as test indices in previous studies of FHP to measure movements of the cervical spine, and their reliability and validity as measures of FHP have been repored (Cheung Lau et al., 2009; Park et al., 2015; Chae, 2002).

Normal range of CVA which was used for measuring FHP was below: An angle less than $40^{\circ}$ denoted a severe level of FHP, between $40^{\circ} \sim 48^{\circ}$ denoted a medium level of FHP, between $48^{\circ} \sim 55^{\circ}$ denoted a light level of FHP, and an angle greater than $55^{\circ}$ denoted a normal level of FHP (Salahzadeh et al., 2014). As the FHP is occur, the CVA is getting reduce and normal CRA is bigger than $145^{\circ}$ (Chansirinukor, 2001). The position of the lumbar support fixture applied in this study was located at lumbar segments L1-L5 to prevent lordosis of the lumbar spine and to maintain neutral positioning of the pelvis. The position of the thoracic support fixture was located at the center of T3-T12 to prevent excessive transformation of thoracic kyphosis (Bernhardt, 1989) (Fig. 1). The selected support fixtures were $39 \mathrm{~cm}$ wide, $32 \mathrm{~cm}$ long and $8 \mathrm{~cm}$ thick, were made of air-mesh and high elastic urethane materials (Fig. 2). To enhance the reliability of the measurements, different colored pointers were attached at each position when measuring the angles (Chae, 2002). Digital cameras were positioned at a distance of $.8 \mathrm{~m}$ from the participants, located at a height of the seventh cervical vertebra. The cameras were fixed on tripods to prevent any rotating or tilting (Lau et al., 2010).

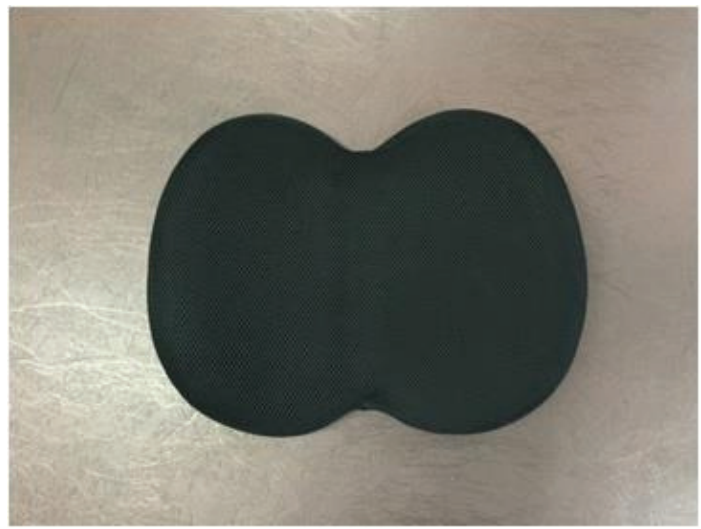

Fig. 2. Support fixture 
Before commencing the typing task, the participants fixed their view on the computer and placed, their elbows on the desk to maintain a comfortable posture. The CVA and CRA were then measured. After conducting the task for $20 \mathrm{~min}$, the changed postures were photographed, without mentioning this to the participants. To enhance the reliability of the results, three researchers measured the angles each time, and the mean values were recorded.

\section{Data Analysis}

SPSS 22.0 for Windows was used for the statistical analysis. The one way analysis of variance was used to compare significant differences among the groups, and Fisher's LSD test was used for post hoc evaluations. All statistical tests were completed at the .05 alpha level.

\section{Results}

The general characteristics of the subjects $(n=36)$ were as follow: mean age was $26.21 \pm 2.72$ years; mean height; $175.92 \pm 6.09 \mathrm{~cm}$, mean weight; $71.50 \pm 6.09 \mathrm{~kg}$.

The comparison of the CVA, CRA according to application thoracic and lumbar support fixtures were as follows:

The experimental groups (thoracic and lumbar support fixtures) had significantly differences than the control group in CVA $(\mathrm{p}<.05)$ (Table 1).

The change of CRA in the experimental groups was significantly difference than the control group $(\mathrm{p}<.05)$ (Table 2).

Thoracic support fixture was decreased in change of CRA than lumbar support fixture and lumbar support fixture was decreased in change of CVA than thoracic support fixture, whereas there were no differences in the level of CVA, CRA between experimental groups ( $\mathrm{p}>.05)$.
Table 1. The comparison of CVA angle, according to application thoracic or lumbar support fixtures

\begin{tabular}{ccc}
\hline Variables & CVA 0 minute & CVA 20 minutes \\
\hline CG & $49.36^{\circ} \pm 3.18^{\dagger}$ & $40.25^{\circ} \pm 5.42^{\mathrm{a}}$ \\
$\mathrm{TS}$ & $53.64^{\circ} \pm 7.41$ & $49.29^{\circ} \pm 8.10^{\mathrm{b}}$ \\
$\mathrm{LS}$ & $51.90^{\circ} \pm 6.16$ & $47.92^{\circ} \pm 7.16^{\mathrm{b}}$ \\
$\mathrm{p}$ & .213 & $.007^{*}$ \\
\hline
\end{tabular}

$\mathrm{Mean} \pm \mathrm{SD}^{\dagger}$

CG; control group TS; thoracic support, LS; lumbar support, CVA; craniovertebral angle, $\mathrm{p}^{*}<.05$, Values with different letters in a column are significantly different by Fisher's LSD test

Table 2. The comparison of CRA angle, according to application thoracic or lumbar supports

\begin{tabular}{ccc}
\hline Variables & CRA 0 minute & CRA 20 minutes \\
\hline CG & $137.83^{\circ} \pm 5.66^{\dagger}$ & $141.66^{\circ} \pm 4.92^{\mathrm{a}}$ \\
$\mathrm{TS}$ & $134.06^{\circ} \pm 6.06$ & $135.21^{\circ} \pm 6.40^{\mathrm{b}}$ \\
$\mathrm{LS}$ & $133.27^{\circ} \pm 4.93$ & $134.53^{\circ} \pm 4.85^{\mathrm{b}}$ \\
$\mathrm{p}$ & .116 & $.005^{*}$ \\
\hline
\end{tabular}

$\mathrm{Mean} \pm \mathrm{SD}^{\dagger}$

CG; control group, TS; thoracic support, LS; lumbar support, CRA; craniorotation angle, $\mathrm{p}^{*}<.05$, Values with different letters in a column are significantly different by Fisher's LSD test

\section{Discussion}

Long hours of sedentary work using computers increase overall spinal bending. At the same time, maintaining normal lordosis of the lumbar spine controls kyphosis of the thoracic spine and has an indirect effect on the cervical spine. Maintaining appropriate kyphosis of the thoracic spine also has a direct effect on the cervical spine and is effective in correcting FHP (Quek et al., 2013; Kendall, 2010).

For these reasons and for the overall alignment of the spine, the use of a support fixture affects head positioning, viewing angle, the vestibular system, and the proprioception of the neck; it also eventually decreases the neuromuscular 
activities that influence not only muscle fatigue but also FHP (Goda, 2015; Ko, 2011).

This study attempted to explore the effects on FHP of applying thoracic and lumbar support fixtures. The research obtained the following results. Targeting ordinary persons, the observation showed that after 20 minutes of a computer task, there was a 9.1 degree decrease of CVA and a 3.8 degree increase of CRA in the group with no support fixture. In the group with the thoracic support fixture, there was a $4.4^{\circ}$ decrease of CVA and a $1.2^{\circ}$ of CRA and in the group with the lumbar support fixture, there was a $4^{\circ}$ decrease of CVA and a $1.3^{\circ}$ increase of CRA. This shows that the group with no support fixture had a greater decrease of CVA and a greater increase of CRA compared to the groups with support fixtures.

This implies that the group with no support fixture experienced greater FHP compared to the groups with support fixtures due to an increase in the flexion of the lower cervical spine and the extension of the upper cervical spine (Sahrmann, 2011; Salahzadeh et al., 2014). However, when we compared the effects of thoracic and lumbar support fixtures during computer work, there was no significant difference in CVA decrease or CRA increase between the two groups. But when the mean values were compared, there was a lower decrease of CVA in the lumbar support fixture group and a lower increase of CRA in the thoracic support fixture group. Even though the groups did not show statistically significant differences according to the position of application of the support fixtures, each position may have a different effect on the flexion of the lower cervical spine and the extension of the upper cervical spine.

A smaller CVA angle which was showed by subjects with FHP indicates that the flexion of the lower cervical has been increased, and a greater CRV angle means that the extension of the upper cervical has been increased (Chae, 2002; Raine and Twomey, 1997).

If the cervical spine is normal in the state of thoracic kyphosis, the head will lean forward and in a lower direction. However, as the eyes try to maintain the same viewing height, the upper cervical spine will be extended, and the head will be raised (Kendall, 2010). In addition, the lumbar support prevented forward head posture as it affected the upper and lower cervical spines by creating an appropriate lordosis tilt angle of the pelvis (Ko, 2011). Therefore, even though there was no significant difference in this research, the decrease in the average change of CRA when applying the thoracic support fixture had relatively more effect on the thoracic alignment in decreasing the extension of the upper cervical spine. On the other hand, the decrease in the average change of CVA had a relatively greater effect on the decrease of flexion of the lower cervical spine (Goda, 2015).

It is thought, in this study, that the two supports affected both upper and lower cervical spines. However, rather than using the lumbar support to create an appropriate lordosis tilt angle of the pelvis to indirectly prevent forward head posture, keeping one's eyes level with the thoracic support, which directly prevents thoracic kyphosis, as was argued by Kendall (2010), can reduce the extension of the upper cervical spine. In other words, it can further reduce the increase of CRA. Support fixtures can be useful in maintaining the normal posture of the head and neck when working for more than twenty minutes in a sitting posture. However, there were limitations to observe differences between the thoracic support and the lumbar support within twenty minutes. In further studies, it will be necessary to conduct in-depth research on the effects of a thoracic support fixture on the overall alignment of the spine as well as to analyze the difference between the thoracic and the lumbar support fixtures in targeting subjects with FHP. Also, for a more precise assessment, it will be necessary to classify the sizes of support fixtures based on the curves, using an electromyography (EMG) and X-ray tests to apply to different segments of the spine. 


\section{Conclusion}

This study was conducted to research on the effects of thoracic and lumbar support fixtures on FHP during VDT work. The thoracic and lumbar support fixtures group and control group executed VDT takes for twenty minutes. As a result, when we compared the effects of thoracic and lumbar support fixtures during VDT work, there was no significant difference in CVA and CRA between the two groups. However, the experimental group showed significant changes in the CVA and CRA than control group. Furthermore, these findings indicate support fixtures of the thoracic and lumbar are effective at improving FHP in VDT work.

\section{References}

Bernhardt M, Bridwell KH. Segmental analysis of the sagittal plane alignment of the normal thoracic and lumbar spines and thoracolumbar junction. Spine. 1989; 14(7):717-21.

Chae YW. The measurement of forward head posture and pressure pain threshold in neck muscle. J Kor Soc Phys Ther. 2002;14(1):117-24.

Chansirinukor W, Wilson D, Grimmer K, et al. Effects of backpacks on students: measurement of cervical and shoulder posture. Aust J Physiother. 2001;47(2): 110-6.

Cheung Lau HM, Wing Chiu TT, Lam TH. Clinical measurement of craniovertebral angle by electronic head posture instrument: a test of reliability and validity. Man Ther. 2009;14(4):363-8.

Chiu TT, Ku WY, Lee MH, et al. A study on the prevalence of and risk factors for neck pain among university academic staff in Hong Kong. J Occup Rehabil. 2002;12(2):77-91.

Cuccia AM, Carola C. The measurement of craniocervical posture: a simple method to evaluate head position. Int J Pediatr Otorhinolaryngol. 2009;73(12):1732-6.

Feffari R, Russell AS. Neck pain. Best Pract Res Clin Rheumatol. 2003;17(1):57-70.

Goda H, Hatta T, Kishigami H, et al. Does a Novel-Developed Product of Wheelchair Incorporating Pelvic Support Prevent Forward Head Posture during Prolonged Sitting? PLoS One. 2015;10(11):1-15.

Heo SY. The effects of hold-relax and active stretching on recoveries of muscle fatigue after computer work Mastrer's Degree. Catholic University of Pusan. 2006.

Kendall FP, McCreary EK, Provance PG, et al. Muscle testing and function with posture and pain $\left(5^{\text {th }}\right.$ ed). Baltimore. Lippincott Willians\&Wilkins. 2010.

Ko SH, Kim YS, Yoon BC. The influence of the lumbar spine adjustment using the lumbar roll support on head and neck posture in older adults. J of Contents Association. 2011;11(12):800-6.

Lau KT, Cheung KY, Chan KB, et al. Relationships between sagittal postures of thoracic and cervical spine, presence of neck pain, neck pain severity and disability. Man Ther. 2010;15(5):457-62.

Lee WH. Effect of Distance Between Trunk and Desk on Forward Head Posture and Muscle Activity of Neck and Shoulder Muscles During Computer Work. J Korean Soc Phys Med. 2013;8(4):601-8.

Mckenzie RA, May S. The lumbar spine: Mechanical Diagnosis and Therapy $\left(2^{\text {th }}\right.$ ed). Waikanae. Spinal Publications. 2003.

Mekhora K, Liston CB, Nanthavanij S, et al. The effect of ergonomic intervention on discomfort in computer users with tension neck syndrom. Int J Ind Ergon. 2000;26(3):367-79.

Park HK, Lee SY, Kim TH. The Exception Case about the Diagnose Forward Head Posture using the CranioVertebra Angle, CranioRotation Angle and Cobb angle: a Case Report. J Korean Soc Phys Med. 2015;10(2):29-34. 
Quek J, Pua YH, Clark RA, et al. Effects of thoracic kyphosis and forward head posture on cervical range of motion in older adults. Man Ther. 2013;18(1):65-71.

Raine S, Twomey LT. Head and shoulder posture variations in 160 asymptomatic women and men. Arch Phys Med Rehabil. 1997;(11):1215-23.

Sahrmann, Shirley A. Movement system impairment syndromes of the extremities, cervical and thoracic spines. St. Louis. Elsevier. 2011.

Salahzadeh Z, Maroufi N, Ahmadi A, et al. Assessment of forward head posture in females: observational and photogrammetry methods. J Back Musculoskelet Rehabil. 2014;27(2):131-9.
Szeto GP, Straker LM, O'Sullivan PB. A comparison of symptomatic and asymptomatic office workers performing monotonous keyboard work--1: neck and shoulder muscle recruitment patterns. Man Ther. 2005;10(4):270-80.

Ukita A, Nishimura S, Kishigami H, et al. Backrest Shape Affects Head-Neck Alignment and Seated Pressure. J Healthc Eng. 2015;6(2):179-92.

Yoo KT, Lee HS. Effects of Therapeutic Exercise on Posture, Pain and Asymmetric Muscle Activity in a Patient with Forward Head Posture: case report. J Korean Soc Phys Med. 2016;11(1):71-82. 